\title{
Análise da Eqüidade e da Eficiência dos Estados no Contexto do Federalismo Fiscal Brasileiro ${ }^{\star}$
}

\author{
- Celso Vila Nova de Souza júnior * - Carlos Eduardo Gasparini **
}

\begin{abstract}
RESUMO
O artigo avalia em que medida o Fundo de Participação dos Estados (FPE) atende aos objetivos redistributivos traçados pela Constituição Federal bem como o seu impacto sobre a eficiência da gestão pública. Emprega-se a Análise de Componentes Principais (ACP) e a Análise de Envoltória de Dados (DEA) para estimar a eficiência relativa dos 27 Estados brasileiros em três etapas. Na primeira, constrói-se uma fronteira de melhor disponibilidade de serviços para avaliar a eqüidade distributiva entre os Estados. Em seguida, uma função custo é usada para se obter um índice de eficiência dos gastos públicos. Na terceira etapa estima-se uma fronteira que descreve a eficiência arrecadatória. Mediante a integração dessas três análises obtém-se o nível ótimo de transferências do FPE. Os resultados mostram que a região Sul apresentou a melhor disponibilidade de serviços e a maior eficiência no uso dos recursos. No extremo oposto encontra-se o Nordeste, onde há fortes carências e também grande desperdício. Quanto ao esforço de arrecadação, não se evidenciaram perdas tributárias acentuadas. $O$ estudo conclui que todos os Estados necessitam de complementação de verbas, mas constata distorções presentes no atual critério.
\end{abstract}

Palavras-CHAVE

eqüidade, eficiência, Análise de Envoltória de Dados (DEA), Análise de Componentes Principais (ACP)

\begin{abstract}
This article evaluates whether the State Participation Fund (FPE) achieves the redistributive goals established by the Federal Constitution, as well as its impact on public administration efficiency. We use Principal Component Analysis (PCA) and Data Envelopment Analysis (DEA) in order to estimate the relative efficiency of the 27 Brazilian states in three steps. First, we build an optimal public service supply frontier in order to evaluate the distributive equity among states. Then, we use a cost function to obtain a public expenditure efficiency index. Third, we estimate a frontier that describes tax revenue efficiency. Integrating these three analyses, we obtain the optimal level of transfers from the FPE. The results show that the Southern region presented the best public service supply and the most efficient resource use. In the opposite side, there is the Northeastern region, where there is strong lack of public good provision and great resource waste. In what concerns tax revenue effort, there is no evidence of relevant tributary losses. We conclude that all states need some federal transfer supplement, but we find distortions in the current criterion.
\end{abstract}

KEY WORDS

equity, efficiency and DEA (Data Envelopment Analysis), PCA (Principal Component Analysis)

\author{
JEL Classification \\ H7, H77, H5
}

+ Os autores agradecem os valiosos comentários e sugestões feitas por dois pareceristas anônimos. Os erros e imprecisões remanescentes são de inteira responsabilidade dos autores.

* Mestre em Economia pela Universidade Católica de Brasília - UCB e Doutorando em Economia pela Tulane University-New Orleans. E-mail: csouza@tulane.edu. Endereço para contato: Department of Economics - 206 Tilton Hall - Tulane University - 6823 - St. Charles Avenue - New Orleans, LA - 70118 - EUA.

* Doutor em Economia pelo PIMES/UFPE e professor da Universidade Católica de Brasília - UCB. E-mail: gasparini@ucb.br. Endereço para contato: SGAN 916 Av. W5, sala A - II7 - Universidade Católica de Brasília, Campus II. Brasília - DF, Brasil. CEP 70790-I60.

(Recebido em agosto de 2005. Aceito para publicação em fevereiro de 2006). 


\section{INTRODUÇÃO}

As disparidades socioeconômicas regionais no Brasil fazem a União enfrentar o desafio de transferir parte de suas receitas tributárias para os demais entes federados (Estados e municípios), de modo a reduzir eventuais desequilíbrios entre a capacidade de arrecadação local e a demanda por bens e serviços públicos. Diante desse contexto, a Constituição Federal de 1988 ampliou a participação dos níveis estaduais e municipais no uso de transferências, feitas principalmente por meio do Fundo de Participação dos Estados (FPE) e dos Municípios (FPM).

Diversos autores, ${ }^{1}$ entretanto, têm sugerido que, ao lado do caráter distributivo, essas transferências poderiam estar afetando, de maneira negativa, a boa gestão dos recursos públicos. Informações mais abrangentes a respeito do impacto do Fundo de Participação dos Estados (FPE) sobre a eficiência da gestão pública, da arrecadação tributária e sobre a necessidade de serviços públicos estaduais ainda são muito limitadas. Assim, busca-se nesse estudo averiguar em que medida o FPE tem atendido ao inciso II do artigo $161 \mathrm{da}$ Constituição Federal, ${ }^{2}$ haja vista tratar-se de relevante instrumento para a reversão desse quadro de desigualdades.

O presente artigo se propõe a avaliar o atual mecanismo de repasse de verbas intergovernamentais para os 26 Estados e o Distrito Federal, utilizando a metodologia Análise de Envoltória de Dados (DEA) para a estimação de fronteiras. ${ }^{3}$ Mais especificamente, avaliaremos o impacto dessas transferências sobre os gastos públicos, por meio de uma fronteira de custos, que nos permitirá estimar os custos mínimos para cada nível de serviços prestados e o respectivo desperdício de recursos. Além disso, usando uma fronteira que descreve a relação entre receitas próprias e algumas variáveis indicadoras da base tributária, estimaremos o potencial de arrecadação dos Estados e do Distrito Federal. Finalmente, uma fronteira de melhor disponibilidade de serviços para necessidades semelhantes, que parte do princípio da eqüidade, ${ }^{4}$ nos permitirá verificar a necessidade de serviços em cada Estado.

O Brasil é um país de grande dimensão territorial, marcado por desigualdades socioeconômicas regionais. Conhecer o seu atual sistema de transferências compensatórias de verbas públicas, de forma a identificar e propor soluçốes para eventuais falhas, torna-se

1 Mendes (1994), Shah (1994), Reis e Blanco (1996), Cossio (1998), Serra e Afonso (1999), Schwengber e Ribeiro (1999), Maia Gomes e Mac Dowell (2000), Gasparini e Melo (2004), entre outros.

$2 \mathrm{O}$ art. 161, inciso II, estabelece normas sobre a entrega dos recursos de que trata o art. 159, especialmente sobre os critérios de rateio dos fundos previstos em seu inciso I, objetivando promover o equilíbrio socioeconômico entre Estados e Municípios.

3 Seiford e Thrall (1990) fornecem uma descrição detalhada da metodologia.

4 O princípio da eqüidade reconhece que os indivíduos são diferentes entre si e propõe que a distribuição dos bens e serviços seja feita de forma a reduzir a desigualdade entre eles. Esse princípio admite que uso igual deve ser proporcionado para necessidades idênticas. Avaliações mais detalhadas podem ser obtidas nos trabalhos de Medeiros (1999) e Gasparini e Ramos (2004). 
uma questão extremamente relevante diante da grande demanda por bens e serviços públicos. Descobrir um montante ótimo de repasse de verbas para os Estados da Federação, numa perspectiva ampla, é de fundamental importância para garantir provisão eficiente e eqüitativa de bens e serviços públicos.

$\mathrm{O}$ artigo está organizado em cinco seções, incluindo esta introdução. Na próxima seção apresenta-se a metodologia utilizada, baseada em técnicas não-paramétricas (DEA) de estimação de fronteiras de eficiência e no uso da técnica de Análise de Componentes Principais (ACP) com objetivo de reduzir a dimensionalidade das variáveis. A base de dados está descrita na segunda seção. Na seção 3 são discutidos os resultados. Por fim, a parte final resume as principais conclusões a que o trabalho permite chegar.

\section{METODOLOGLA DE AVALIAÇÃO DA EFICIÊNCIA E DA EQÜIDADE}

A proposta de avaliação do FPE no presente trabalho seguirá a abordagem sugerida por Gasparini e Melo (2004) e se baseia em alguns conceitos e procedimentos bastante utilizados pela Ciência Econômica. Em especial, será estimada uma fronteira pouco usual na economia, concebida inicialmente por Puig-Junoy (1999), e que permite a mensuração do déficit relativo de serviços. Levaremos em conta ainda as fronteiras de potencial arrecadatório e de custos dos serviços disponíveis. Com relação à fronteira de potencial de arrecadação, a envoltória é superior e corresponde à máxima quantidade de recursos que a utilização das bases tributárias legais podem gerar; quanto à fronteira custos, a envoltória é inferior e diz respeito à obtenção de um dado nível de produto ao menor custo. No tocante à fronteira de melhor disponibilidade de serviços para necessidades iguais, avalia-se o máximo de serviços públicos disponíveis para localidades com necessidades semelhantes (envoltória superior).

FIGURA I - FRONTEIRA EFICIENTE

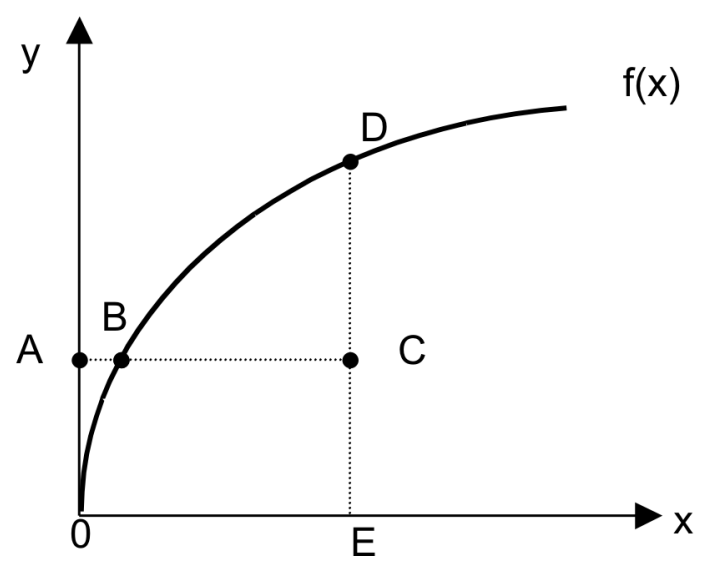


A Figura 1 ilustra a intuição por trás da estimação de fronteiras de eficiência. Tomemos como exemplo uma função de produção, em que $x$ representa um input e $y$ representa um output. A máxima quantidade de produto que a utilização de $x$ pode gerar é representada por $f(x)$, ou seja, a função de produção. Nota-se que o ponto $C$, situado abaixo da fronteira, indica uma região factível de produção. No entanto, esse ponto significa que se está empregando $O E$ unidades de $x$ para produzir $O A$ unidades de $y$. Ao operar abaixo da fronteira, esse plano de produção é considerado ineficiente, pois, dada a tecnologia disponível, não se emprega da melhor forma os recursos. Por outro lado, o ponto $B$ é dito eficiente, já que produz a mesma quantidade de output utilizando a menor quantidade de input possível. O ponto $D$ também representa um plano de produção tecnicamente viável e eficiente, com o qual se obtém o máximo de output, utilizando a mesma quantidade de input.

De modo semelhante, a Figura 1 pode representar a fronteira de serviços, que representa a melhor oferta disponível para determinado nível de necessidades. A construção dessa fronteira parte da idéia de que a mesma oferta de serviços deve estar disponibilizada para necessidades semelhantes, atendendo ao princípio distributivo da eqüidade. Estar situado abaixo da fronteira significa déficit relativo dos serviços em questão.

O marco inicial para a discussão de fronteiras e medidas de eficiência é o trabalho de Farrell $(1957)^{5}$ e, posteriormente, de Charnes, Cooper e Rhodes (1978), que generalizaram o estudo, estendendo o modelo para múltiplos recursos e resultados na obtenção de um indicador que atendesse ao conceito de eficiência de Koopmans (1951). ${ }^{6}$ A partir de então, a técnica de construção de fronteiras de eficiência tem sido bastante difundida, tornando-se conhecida (no seu ramo não-paramétrico) como Data Envelopment Analysis (DEA) ${ }^{7}$

Este trabalho utilizará a metodologia de envoltória de dados DEA, cuja estimação é obtida pelo método de programação linear. As principais diferenças entre a abordagem não-paramétrica, aqui empregada, e as versões paramétricas residem no fato de as últimas exigirem a imposição de determinada forma funcional para a fronteira (especificada por parâmetros constantes) e basearem os processos de estimação (procedimentos econométricos) em valores centrais. O método DEA, por sua vez, é desenhado especificamente para estimaçôes de fronteiras (envoltórias) e requer apenas algumas propriedades incorpo-

5 A partir daí surge uma vasta literatura com inúmeras abordagens alternativas. Ver, por exemplo, Forsund, Lovell e Schmidt (1980), Bauer (1990) e Seiford e Thrall (1990).

6 Eficiência no sentido de Pareto-Koopmans existe quando um plano de operação satisfaz as seguintes condições: 1) um produto não pode ser gerado em maior quantidade sem que seja diminuída a quantidade gerada de algum outro produto ou sem que seja aumentada a quantidade consumida de pelo menos um insumo; 2) um insumo não pode ser consumido em menor quantidade sem que seja aumentada a quantidade consumida de algum outro insumo ou sem que seja diminuída a geração de pelo menos um produto.

7 De um modo geral, as abordagens para definir fronteiras de eficiência podem ser separadas em dois grupos: métodos paramétricos e não-paramétricos. 
radas ao processo produtivo, tais como livre descarte (free disposal) e convexidade. ${ }^{8}$ Além disso, as hipóteses assumidas para a relação entre imputs e outputs consideram a existência ou não de retornos de escala (crescentes, decrescentes, variáveis ou constantes).

Vale ressaltar algumas vantagens importantes dessa abordagem para os fins propostos neste trabalho: i) flexibilidade para trabalhar com múltiplos inputs e outputs; ii) foco em observações individuais em contraste com as médias da amostra; iii) fornece estimativa robusta de eficiência relativa; iv) é livre de unidades de medida; v) não impõe forma funcional à fronteira; vi) a ponderação das variáveis não sofre qualquer influência exógena no processo de estimação.

\subsection{Construção da Fronteira de "Melhor Disponibilidade de Serviços para Idênticas Necessidades"}

O interesse aqui é medir a eqüidade dos Estados brasileiros na provisão dos serviços públicos. Para conceituar formalmente a medida de eqüidade dos serviços disponibilizados, levamos em conta os Estados da Federação Brasileira $(j=1,2, \ldots, m)$, caracterizados por um sistema de produção múltipla representado por um vetor de serviços disponíveis $y_{j}=\left(y_{j 1}, y_{j 2}, \ldots, y_{j D}\right), y \in R_{+}^{D}$, e por um vetor de necessidades $n_{j}=\left(n_{j 1}, n_{j 2}, \ldots, n_{j V}\right), n_{j} \in R_{+}^{V}$, ou seja, cada Estado tem $(d=1,2, \ldots, D)$ serviços disponíveis e $(v=1,2, \ldots, V)$ necessidades que precisam ser atendidas, o que determina um plano de operação descrito pelo vetor $(n, y) \in R_{+}^{D+V}$. Assim, definimos a seguinte relação entre $y$ e $n: T=\left\{(n, y) \in \mathfrak{R}_{+}^{D+V}: n\right.$ é satisfeito por $\left.y\right\}$. Desta forma, um conjunto de oferta de serviços $y$ que satisfaz o nível de necessidades $n$ pode ser estabelecido como: $P(n)=\left\{y \in \mathfrak{R}_{+}^{D}:(n, y) \in T\right\}, \forall n \in \mathfrak{R}_{+}^{V}$.

Um plano de operação $(n, y)$ é dito ser eficiente, ou seja, refletir a melhor disponibilidade de serviços se não existir nenhum outro que ofereça nível maior de serviços para o mesmo conjunto de necessidades, podendo ser representada da seguinte maneira: front $P(n)=\left\{y \in p(n) / y^{\prime} \geq y\right.$ e $\left.y^{\prime} \neq y \Rightarrow y^{\prime} \notin P(n)\right\}, \forall n \in \mathfrak{R}_{+}^{V}$.

O índice de eficiência para o Estado que está sendo avaliado será representado por $\Psi_{0}$ e o seu plano de operação, respectivamente, por $\left(n_{0}, y_{0}\right)$. A medida de déficit relativo de serviços, $\Psi$, permite identificar os Estados mais eficientes e quantificar possibilidades de ampliação dos serviços para idênticas necessidades. O déficit corresponde à proporção

8 Essa propriedade permite combinar planos observados para gerar novos planos de operações viáveis, isto é, qualquer combinação convexa de planos de operação observados é também um plano de operação viável. 
entre o vetor de serviços realizados pelo Estado e o vetor de resultados ótimos (obtido pela projeção radial eqüiproporcional do vetor observado sobre a fronteira de eficiência) e pode ser representado por: $\Psi(n, y)=\max \{\lambda: \lambda * y \in P(n)\}$. Se $\Psi_{j}>1$, o Estado é dito ser ineficiente e o valor obtido corresponde à taxa pela qual os serviços podem ser ampliados para atingirem a fronteira, dadas as necessidades observadas. Por outro lado, $\Psi_{j}=1$ indica que nenhuma expansão eqüiproporcional é possível para o vetor de serviços. O coeficiente de um Estado particular, $\Psi_{0}$, pode ser obtido por meio da resolução do seguinte problema de programação linear: ${ }^{9}$

$$
\Psi_{0}\left(n_{j}, y_{j}\right)=\underset{\{\lambda, h, \sigma, s\}}{\operatorname{Maximizar}} \lambda_{0}+\varepsilon\left(\sum_{d} \sigma_{d}+\sum_{v} s_{v}\right)
$$

Sujeito a

$$
\begin{array}{lr}
\sum_{j} h_{j} \cdot y_{j d}-\sigma_{d}=\lambda_{0} \cdot y_{0 d} & d=(1,2, \ldots, D) \\
\sum_{j} h_{j} \cdot n_{j v}+s_{i}=n_{0 v} & v=(1,2, \ldots, V) \\
\sum_{j} h_{j}=1 & j=(1,2, \ldots, m) \\
\lambda_{j}, \sigma_{j}, h_{j} \geq 0, s_{v} \geq 0 . &
\end{array}
$$

Resolvendo o problema (l) para cada unidade decisória (DMU) é possível encontrar o déficit relativo de serviços para cada Estado, $\Psi_{j}$. Os valores dos multiplicadores $(\varepsilon)$ servem como ponderador de um agregado de excessos e folgas. Além disso, a introdução das variáveis representativas de folga na produção $\sigma_{r}$ e dos excessos no consumo $s_{i}$ permite obter as condições de otimalidade de Pareto-Charnes et alii (1994). ${ }^{10}$ Os pesos atribuídos aos vetores de necessidades e disponibilidades de serviços $\left(h_{j}\right)$ são aqueles que minimizam a distância entre cada Estado e a fronteira de melhor disponibilidade de serviços.

Diferentes hipóteses sobre os retornos de escala definem fronteiras distintas, que possibilitam a separação da ineficiência produtiva em componentes associados à escala de operação e às falhas na gestão da organização. Dadas as diferenças marcantes entre os

9 A formulação desse problema corresponde ao modelo DEA-BCC, devido a Banker, Charnes e Cooper (1984), orientado para output.

10 Charnes, Cooper e Rhodes (1978) propõem um modelo de avaliação de eficiência que, mesmo mantendo o princípio da projeção radial sobre a fronteira, trabalha com as folgas e os excessos existentes para construir um indicador que atenda ao conceito de eficiência de Koopmans. 
Estados brasileiros, será assumida em todos os modelos a hipótese de retornos variáveis de escala.

\subsection{Construção da Fronteira de Eficiência dos Gastos Públicos}

Visando avaliar os repasses do FPE, foi realizada uma verificação da eficiência em custos da prestação dos serviços públicos estaduais (saúde, educação, justiça, segurança, bens públicos e outros). Partiu-se da estimação de uma fronteira de custos, que é especificada a partir do preço dos insumos $(w)$ e da quantidade de serviços prestados $(y)$. Como a estimação está sendo feita para determinado instante de tempo, considerou-se que os preços dos imputs ficaram inalterados e foram os mesmos para todos os estados. Com isso, a função custo pode ser representada por $C(y)$.

Para a estimação deste problema, será utilizado o modelo DEA-BCC orientado para os imputs, supondo retornos variáveis de escala. Para calcular as medidas de eficiência faz-se necessário resolver o seguinte problema de programação linear:

$$
\Phi_{0}\left(C_{j}, y_{j}\right)=\underset{\{\theta, h, \sigma, s\}}{\operatorname{Minimizar}} \theta_{0}-\varepsilon\left(\sum_{d} \sigma_{d}+\sum_{v} s_{v}\right)
$$

Sujeito a

$$
\begin{aligned}
& \sum_{j} h_{j} \cdot y_{j d}-\sigma_{d}=y_{0 D} \quad d=(1,2, \ldots, D) \\
& \sum_{j} h_{j} \cdot C_{j}+s_{v}=C_{0} \cdot \theta_{0} \quad v=(1,2, \ldots, V) \\
& \sum_{j} h_{j}=1 \quad j=(1,2, \ldots, m) \\
& \theta_{j}, \sigma_{j}, h_{j} \geq 0, s_{v} \geq 0 .
\end{aligned}
$$

A solução do problema (2) nos permitirá obter o índice que indica a máxima contração eqüiproporcional no vetor de custos (despesas correntes) dos 27 Estados brasileiros mantendo-se inalterado o nível de serviços finais. A inclusão posterior do vetor de serviços eqüitativos $\left(y^{*}\right)$ nessa fronteira nos permitirá avaliar o vetor de custos mínimos ótimos para a prestação de serviços em cada Estado. 


\subsection{Construção da Fronteira de Eficiência na Arrecadação Tributária}

Debate-se que alguma ineficiência arrecadatória por parte dos Estados pode estar atrelada ao recebimento de verbas da União. Na estimação deste terceiro modelo - Eficiência arrecadatória - faz-se uma avaliação da arrecadação efetuada pelos Estados para financiar seus gastos.

Para estimar o potencial arrecadatório e avaliar o empenho de cada Estado na obtenção das suas respectivas receitas será especificada uma fronteira de arrecadação que representa a relação entre receita tributária estadual $(R T)$, de um lado, e uma série de variáveis indicadoras de base tributária, $B_{j}=\left(B_{j 1}, B_{j 2}, \ldots, B_{j F}\right)$, de outro. Utilizaremos, também neste caso, o modelo DEA-BCC, supondo retornos variáveis de escala, pelas razões já mencionadas, orientado para o output. O índice de eficiência poderá ser obtido a partir da resolução do seguinte problema de programação linear:

$$
\Omega_{0}\left(B_{j}, R T_{j}\right)=\underset{\{\lambda, h, \sigma, s\}}{\operatorname{Maximizar}} \lambda_{0}+\varepsilon\left(\sum_{f} \sigma_{f}+\sum_{f} s_{f}\right)
$$

Sujeito a

$$
\begin{array}{ll}
\sum_{j} h_{j} \cdot R T_{j}-\sigma_{f}=\lambda_{0} \cdot R T_{0} & f=(1,2, \ldots, F) \\
\sum_{j} h_{j} \cdot B_{j f}+s_{f}=B_{0 f} & j=(1,2, \ldots, m) \\
\sum_{j} h_{j}=1 & \\
\lambda_{j}, h_{j}, \sigma_{j} \geq 0, s_{f} \geq 0 . &
\end{array}
$$

Com base no indicador de eficiência na atividade tributária, calculado para cada Estado, é possível obter a fronteira de arrecadação $R T^{*}(B)$, ou seja, a arrecadação máxima para aquele nível de base tributária, cuja comparação com a arrecadação efetiva $R T(B)$ permite revelar o montante de receita negligenciada pelos Estados brasileiros.

\subsection{Distribuição Ótima das Transferências Redistributivas}

Finalmente, as análises anteriores serão integradas para se obter o repasse ótimo de transferências $\left(T^{*}\right)$ para cada Estado, o que será feito levando-se em consideração a oferta eqüitativa de serviços estaduais $\left(y^{*}\right)$, o custo mínimo para a prestação dos mesmos 
$\left(C^{*}\left(y^{*}\right)\right)$ e o potencial de arrecadação disponível em cada Estado $\left(R T^{*}\right)$. Assim, o repasse recomendado deve corresponder à diferença entre o custo mínimo de se prover o vetor de serviços eqüitativos e o potencial de arrecadação de cada Estado, podendo ser assim representado: $T^{*}=C^{*}\left(y^{*}\right)-R T^{*}$.

Com base nesse critério, ${ }^{11}$ os Estados teriam verbas suficientes para a eficiente prestação de serviços que atenderiam eqüitativamente às necessidades dos 27 Estados brasileiros. As transferências contribuiriam para a compensação de possíveis limitações de arrecadação de cada Estado na prestação ótima dos serviços, permitindo a oferta eqüitativa dos mesmos.

\subsection{Componentes Principais}

Levando-se em consideração que as áreas de saúde, educação, segurança, justiça e serviços diversos são complexas e caracterizadas por uma vasta gama de variáveis, tornou-se necessário empregar uma técnica estatística de redução de dimensionalidade. Tal fato se deve à sensibilidade da técnica DEA em relação a um número muito grande de variáveis relativamente ao número de Estados a serem analisados, provocando a colocação de grande parte desses Estados sobre as fronteiras de eficiências.

No presente trabalho será aplicada a técnica de análise dos componentes principais (ACP), com a finalidade de simplificar a estrutura dos dados, ou seja, reduzir a dimensionalidade por intermédio da seleção dos componentes principais. A ACP procura descrever, com maior parcimônia, a estrutura de dependência das variáveis observáveis, sem um modelo estatístico previamente definido.

Seja $p$ o conjunto de variáveis observadas sobre $q$ elementos, formando um conjunto de dados $X(p \times q)$. Essa técnica descreve a configuração dos elementos no espaço das variáveis, onde os componentes principais determinam as direções de maiores variações nos pontos observados. Os componentes principais extraídos serão combinações lineares das $p$ variáveis, de forma tal que o primeiro componente principal $C_{1}$ tenha variância máxima. Assim, o primeiro componente principal $\left(C_{1}\right)$ é uma combinação linear de $X$ que configura as variáveis na direção de maior dispersão, ou seja, na direção da maior parte da variação nos pontos observados. O segundo componente principal $\left(C_{2}\right)$ é outra combinação linear de $X$ com a segunda maior variância, sendo ortogonal a $C_{1}$, e assim

11 Ver Gasparini e Mello (2004) para mais detalhes. 
por diante. Isto equivale a dizer que os componentes principais não são autocorrelacionados. ${ }^{12}$

Os componentes principais dependem da matriz de correlação $(r)$ ou da matriz de covariância $(S)$ de $x_{1}, x_{2}, \ldots, x_{p}$. O seu desenvolvimento não necessita da suposição de normalidade. Na extração dos componentes, as variâncias são decrescentes devido à restrição crescente de não autocorrelação entre elas, ou seja, os últimos componentes têm variâncias tão pequenas que podem ser eliminados.

\subsubsection{Determinação dos Componentes Principais}

No presente estudo, a seleção dos componentes principais tomou por base a proporção da variância explicada por cada um deles. A variância de cada componente principal representa um autovalor da matriz de covariância amostral. Assim que todos os componentes são extraídos, a variância do conjunto de dados é totalmente reproduzida. A variância total é a soma da diagonal principal da matriz de covariância amostral $(S)$, que é o traço da matriz $(t r S)$ e pode ser representado da seguinte forma: variância total $=\delta_{1}+\delta_{2}+\ldots+\delta_{p}=t r S$. A parcela da variância explicada por cada componente principal (w) pode ser obtida pela seguinte expressão: $w=\frac{\delta_{h}}{\sum_{i=1}^{p} \delta_{i}}$. O subgrupo de variáveis selecionadas representará o melhor resumo da variância total do conjunto inteiro de variáveis sem perda de informação relevante.

No entanto, o método de análise dos componentes principais pode apresentar valores tanto positivos como negativos. A existência de valores negativos no método DEA pode causar problemas na determinação dos escores de eficiência, ou seja, gerar situações em que pode ocorrer colapso em seu cálculo. Vários autores têm estudado o assunto, sugerindo alternativas. Os procedimentos propostos estão baseados em propriedades invariantes das medidas de eficiência em relação a transformações afins das variáveis. ${ }^{13}$

12 Geometricamente, essas combinações lineares representam um novo sistema de coordenadas obtido por um deslocamento rotacional do sistema original $X_{1}, X_{2}, \ldots, X_{p}$. Os novos eixos representam as direçóes de variabilidade máxima e fornecem uma descrição mais simples e mais parcimoniosa da estrutura de covariância.

13 Nos modelos DEA-BCC, Ali e Seiford (1990) mostram que esse tipo de transformação pode ser aplicado sem mudar a definição de unidades eficientes. Pastor (1996) generaliza esses resultados e conclui que modelos DEABCC orientados para o output são invariantes nos termos das transformações afins dos inputs, e aqueles modelos que são orientados para o imput são invariantes às transformações nos outputs. 
Mas, para cada componente principal, $C_{i}=a_{1 i} \cdot X_{1}+\ldots+a_{p i} . X_{p}$, pode-se mostrar que $\operatorname{Cov}\left(X_{j}, C_{i}\right)=\delta_{i} \cdot a_{j i}$. O sinal e a magnitude de $a_{j i}$ indicam o sentido e a contribuição da j-ésima variável para o i-ésimo componente. Neste trabalho, considerou-se o maior coeficiente $a_{j i}$, em valor absoluto, representante da maior associação entre a variável $j$ e o componente $i$.

Com isso, obteve-se a redução da dimensão na estimação das fronteiras de gastos, arrecadação e melhor disponibilidade dos serviços prestados, a partir da substituição de cada um dos $g$ componentes principais selecionados pela respectiva variável com o coeficiente de maior valor em módulo, uma vez que essa variável é a mais representativa da variabilidade do respectivo componente principal. Em síntese, o problema da escolha de variáveis para o modelo com a menor perda de informação possível pôde ser superado.

\section{DEFINIÇÃO DAS VARIÁVEIS (BASE DE DADOS)}

O conjunto de dados utilizado para as estimações dos três modelos propostos foi composto por 28 variáveis distintas. ${ }^{14}$ A idéia do primeiro modelo - Eqüidade dos serviços estaduais - é construir uma fronteira que avalie a distribuição relativa dos serviços públicos entre os Estados brasileiros, partindo das necessidades existentes em cada localidade. Para isso, lançou-se mão de uma fronteira de melhor disponibilidade de serviços para necessidades idênticas, conforme discutido no item 1.1. Busca-se confrontar, nessa estimação, um conjunto de variáveis indicadoras de oferta de serviços (outputs) com um grupo de indicadores de necessidades (imputs). Foram utilizadas dezesseis variáveis que indicassem a disponibilidade relativa de bens e serviços estaduais (nas áreas de saúde, educação, justiça, segurança e serviços diversos), assim como sete variáveis indicadoras de necessidades. Vale ressaltar que os aspectos selecionados em ambos os casos possuem inúmeras dimensões e envolvem diversas formas de atendimento. Para lidar com os serviços Estaduais, procurou-se selecionar indicadores de disponibilidade ou de dificuldades de acesso aos bens e serviços públicos, assim como para as necessidades buscou-se incluir os aspectos demográficos, sociais, epidemiológicos e econômicos.

Uma vez definida a base de dados, aplicou-se a técnica ACP nas sete variáveis de necessidades, para determinar o melhor resumo da demanda por serviços nos Estados. Foram considerados os componentes que representassem até 3\% da variância amostral. Em seguida, foi selecionada a variável com o maior coeficiente absoluto para cada componente principal, como discutido na subseção 1.5.1. O resultado da seleção foram quatro variáveis que representam aproximadamente $99 \%$ da variação total do conjunto analisado, a

14 O conjunto completo das variáveis, a fonte e o ano estão descritos no Anexo I. 
saber: (1) população total, (2) taxa de trabalho infantil, (3) razão de renda e (4) número de residências sem instalações sanitárias.

Dentre as dezesseis variáveis que representam a oferta de serviços, foram selecionadas pelo mesmo procedimento quatro variáveis que descrevem, aproximadamente, $93 \% \mathrm{da}$ variação total. São elas: (1) número de matrículas do ensino fundamental; (2) número de técnicos auxiliares de enfermagem por 1000 habitantes; (3) inverso do número de óbitos violentos; (4) população com mais de 8 anos de estudo.

O segundo modelo - Eficiência em custos - busca estimar uma tradicional função custo e relaciona o custo total dos serviços prestados, por um lado, e com o montante ofertado desses serviços, por outro. Para isso, tomaram-se como indicador dos custos (input) as despesas correntes estaduais. ${ }^{15}$ As variáveis indicadoras da oferta de serviços públicos estaduais (outputs) utilizadas nesse modelo, por uma questão de coerência interna, foram as mesmas do modelo 1 (Fronteira de "Melhor Disponibilidade de Serviços para Idênticas Necessidades") que, como já vimos, foram reduzidas para quatro variáveis que descrevem $99 \%$ da variância total do conjunto analisado.

O último modelo - Eficiência arrecadatória - busca avaliar o esforço tributário dos Estados em função da potencial base de arrecadação. Como indicador de esforço fiscal (output) foram consideradas as Receitas Tributárias Próprias efetivamente arrecadadas. Os indicadores de base tributária procuraram espelhar os principais tributos estaduais. Foram consideradas três variáveis (inputs): Renda Total, População Urbana e Frota de Veículos. Neste modelo não houve a necessidade de se aplicar a $\mathrm{ACP}$, uma vez que as variáveis utilizadas já se encontram em número reduzido.

\section{APRESENTAÇÃO E ANÁLISE DOS RESULTADOS}

\subsection{Primeiro Modelo: Eqüidade dos Serviços Públicos Estaduais}

A Tabela 1 apresenta os resultados do primeiro modelo. Uma forma interessante de analisar o déficit de serviços é tomando o inverso da medida radial $\left(\frac{1}{h_{j}}\right)$, apresentada na terceira coluna. Essa medida indica a proporção de serviços disponíveis para determinado Estado, em relação aos localizados na fronteira de melhor disponibilidade.

15 Trata-se da rubrica de despesa mais abrangente, que não inclui as despesas de capital, não necessariamente relacionadas à prestação de serviços. Apesar dos indicadores de serviços analisados não perfazerem a totalidade desses gastos, as despesas correntes conseguem, como indicador, captar mais integralmente o nível de gastos estaduais. 
TABELA 1 - EQÜIDADE DE SERVIÇOS (BRASIL) - 2002

\begin{tabular}{|c|c|c|c|}
\hline $\begin{array}{l}\text { DMU } \\
\text { Região/Estado }\end{array}$ & Índice de Eficiência $\left(h_{j}\right)$ & Déficit $\frac{1}{h_{j}}$ & PIB PM corrente* \\
\hline Norte (Total) & & & $57.027,00$ \\
\hline Média & 1,059 & 0,949 & $8.146,71$ \\
\hline Desvio Padrão & 0,087 & 0,073 & $9.083,28$ \\
\hline Acre & 1,000 & 1,000 & $1.921,00$ \\
\hline Amapá & 1,000 & 1,000 & $2.253,00$ \\
\hline Amazonas & 1,016 & 0,984 & $20.736,00$ \\
\hline Pará & 1,196 & 0,836 & $21.748,00$ \\
\hline Rondônia & 1,176 & 0,850 & $6.083,00$ \\
\hline Roraima & 1,000 & 1,000 & $1.219,00$ \\
\hline Tocantins & 1,028 & 0,973 & $3.067,00$ \\
\hline Nordeste (Total) & & & $156.852,00$ \\
\hline Média & 1,438 & 0,703 & $17.428,00$ \\
\hline Desvio Padrão & 0,168 & 0,080 & $15.507,06$ \\
\hline Alagoas & 1,748 & 0,572 & $7.569,00$ \\
\hline Bahia & 1,218 & 0,821 & $52.249,00$ \\
\hline Ceará & 1,480 & 0,676 & $21.581,00$ \\
\hline Maranhão & 1,600 & 0,625 & $10.293,00$ \\
\hline Paraíba & 1,267 & 0,789 & $10.272,00$ \\
\hline Pernambuco & 1,443 & 0,693 & $31.725,00$ \\
\hline Piauí & 1,508 & 0,663 & $5.575,00$ \\
\hline Rio Grande do Norte & 1,352 & 0,740 & $9.384,00$ \\
\hline Sergipe & 1,330 & 0,752 & $8.204,00$ \\
\hline Sudeste (Total) & & & $684.730,00$ \\
\hline Média & 1,0290 & 0,9740 & $171.182,50$ \\
\hline Desvio Padrão & 0,0579 & 0,0519 & $161.864,75$ \\
\hline Espírito Santo & 1,116 & 0,896 & $22.538,00$ \\
\hline Minas Gerais & 1,000 & 1,000 & $113.530,00$ \\
\hline Rio de Janeiro & 1,000 & 1,000 & $148.033,00$ \\
\hline$\{X\}$ São Paulo & 1,000 & 1,000 & $400.629,00$ \\
\hline Sul (Total) & & & $213.389,00$ \\
\hline Média & 1,000 & 1,000 & $71.129,67$ \\
\hline Desvio Padrão & 0,000 & 0,000 & $23.816,90$ \\
\hline Rio Grande do Sul & 1,000 & 1,000 & $94.084,00$ \\
\hline Santa Catarina & 1,000 & 1,000 & $46.535,00$ \\
\hline Paraná & 1,000 & 1,000 & $72.770,00$ \\
\hline Centro-Oeste (Total) & & & $86.288,00$ \\
\hline Média & 1,010 & 0,990 & $21.572,00$ \\
\hline Desvio Padrão & 0,018 & 0,017 & $9.236,40$ \\
\hline Distrito Federal & 1,000 & 1,000 & $33.051,00$ \\
\hline Goiás & 1,036 & 0,965 & $25.048,00$ \\
\hline Mato Grosso & 1,000 & 1,000 & $14.453,00$ \\
\hline Mato Grosso do Sul & 1,004 & 0,996 & $13.736,00$ \\
\hline \multicolumn{4}{|l|}{ Brasil (Total) } \\
\hline Média & 1,1673 & 0,8826 & $44.380,96$ \\
\hline Desvio Padrão & 0,0662 & 0,0444 & $43.901,68$ \\
\hline
\end{tabular}

* R\$ Milhão.

$\{\mathrm{x}\}$ Outlier. 
No que se refere à análise por macrorregião, a Região Sul apresentou o melhor resultado. Todos os seus Estados estão situados na fronteira de melhor disponibilidade de serviços. Já a região Centro-Oeste obteve a segunda melhor performance, onde se atinge, em média, 99\% da oferta disponível nas melhores áreas. Dos quatro Estados que compóem a região, apenas Goiás e Mato Grosso do Sul não fizeram parte da fronteira, apresentando déficit de $3,6 \%$ e $0,4 \%$ nos serviços prestados, respectivamente.

A seguir vêm as Regióes Sudeste e Norte, com uma disponibilidade de serviços de 97,4\% e 94,9\%, respectivamente. No Sudeste, todos os Estados desfrutam da melhor disponibilidade de serviços para necessidades idênticas, com exceção do Espírito Santo, que apresentou necessidade de ampliar os atuais serviços prestados em $11 \%$. Fica nítida a situação diferenciada desse Estado em relação aos demais que compõem a região.

No tocante à região Norte, foi possível constatar pouca discrepância entre os Estados, exceto para Rondônia e Pará, que obtiveram 83,6\% e 85\% da oferta disponível dos serviços. Amazonas e Tocantins apresentaram índices de eficiência da ordem de 98,4\% e 97,3\%, respectivamente. Os demais (Acre, Amapá e Roraima) foram considerados eficientes, ou seja, contam com melhor disponibilidade de serviços para as mesmas necessidades. O aparecimento desses Estados na fronteira eficiente exige considerações mais detalhadas, por se tratarem de novas unidades da Federação (ex-territórios), que em geral contam com economias frágeis. Essas considerações servem igualmente para ressaltar algumas características do método aplicado e também a natureza e o significado da estimação efetuada.

Em primeiro lugar, o foco dessa estimação foi o confronto de indicadores de necessidades (sociais, econômicas e demográficas) com a disponibilidade de serviços públicos. Não resta dúvida de que áreas como o Acre, Amapá e Roraima dispóem de menor oferta de serviços públicos estaduais do que o Pará, por exemplo, que ficou bem distante de fronteira (déficit de $15 \%$ em relação à melhor disponibilidade). No entanto, o que a estimação revela é que, diante das necessidades presentes naqueles Estados, a oferta de serviços é comparativamente melhor do que a existente no Pará ou em Rondônia, diante das carências nestes verificadas.

Em segundo lugar, é preciso destacar um aspecto importante da abordagem utilizada: trata-se de uma metodologia comparativa. A performance de uma unidade é o resultado do confronto com os demais elementos da amostra. Neste sentido, a estimação levou em conta a possibilidade de retornos variáveis de escala, exatamente para contemplar a diversidade de porte existente entre os Estados brasileiros. Assim, unidades pequenas são comparadas com seus pares, o mesmo acontecendo com as grandes. Ou seja, a comparação foi feita de modo a permitir que se levasse em conta realidades dessemelhantes, de modo a evitar distorções nos resultados.

Finalmente, cumpre destacar que os novos Estados, exatamente por possuírem diminuta base econômica e pequeno contingente populacional, permitem uma situação na qual 
qualquer acréscimo na oferta de serviços, por pequena que seja, tenha um grande impacto no atendimento das necessidades existentes, colocando-os, em termos relativos, numa situação favorável.

Retomando a análise macrorregional, é possível perceber uma nítida discrepância da região Nordeste em relação às demais, todas acima da média nacional. A situação do Nordeste é digna de nota, dispondo-se ali de não mais que $70 \%$ da oferta de serviços públicos disponíveis em outras áreas. Todos os seus Estados apresentaram necessidade de melhorias para alcançar a fronteira. Para se ter uma idéia da gravidade da situação encontrada nessa região, o Estado em melhor posição está mais longe da fronteira do que o pior entre os demais Estados da Federação. Os nove Estados em pior situação são, em ordem decrescente de atendimento: Bahia (82,1\%), Paraíba (78,9\%), Sergipe $(75,2 \%)$, Rio Grande do Norte (74\%), Pernambuco (69,3\%), Piauí (66,3\%), Maranhão $(62,5 \%)$, Ceará $(67,6 \%)$ e Alagoas (57,2\%). O nível médio (relativo) de atendimento das necessidades na região situa-se em 70,3\%. A pior situação é verificada em Alagoas. Nota-se que os serviços prestados no Estado precisam quase que dobrar para que se atinja a mesma disponibilidade de assistência existente em outros Estados.

A questão regional parece ter um papel importante nesses resultados. O fato dos Estados do Nordeste formarem, em bloco, o conjunto menos favorecido no tocante ao atendimento público é intrigante, em especial quando se observa que nesta região encontram-se Estados importantes do ponto de vista econômico e político no cenário nacional, como é o caso da Bahia, de Pernambuco e do Ceará. A colocação desses Estados no quadro interno nordestino, no entanto, não possibilita maiores esclarecimentos, uma vez que eles estão espalhados, em termos relativos da própria região, ao longo de toda a distribuição (entre os nove Estados, a Bahia ocupa a primeira posição, Pernambuco a quinta e o Ceará a oitava).

Os desvios padrão das Regiões Sul, Sudeste e Norte foram relativamente pequenos (abaixo da média nacional), se comparados com os obtidos pela Região Nordeste, indicando pequena variabilidade relativa nos serviços prestados entre os Estados que as constituem. Por fim, não foi possível constatar indícios de que quanto maior a renda estadual menor é a defasagem (carência) dos serviços prestados. Desta forma, os déficits estão muito mais relacionados com questôes históricas e administrativas, entre outras, do que com questôes de renda.

A partir da análise realizada, evidencia-se situação contrária a um dos objetivos originalmente traçados para o FPE, que seria o de promover o equilíbrio socioeconômico entre os Estados federados. Mesmo levando em consideração o conceito da eqüidade (focalização), a situação ainda continua bastante desigual, principalmente para a região Nordeste. O estabelecimento de qualquer padrão, entretanto, exigiria a realização de outros estudos, além do escopo deste trabalho, que considerassem as particularidades da situação. Exemplo disto é o aparecimento de Estados importantes com situação sofrível, 
não só na região mais pobre, como destacamos, mas também no Norte, como é o caso do Pará, e no Sudeste, como é o caso do Espírito Santo.

Esses resultados, todavia, devem ser interpretados com cautela. ${ }^{16}$ Em primeiro lugar, os indicadores representativos de cada área (saúde, educação, justiça, segurança e serviços diversos) são complexos e podem conter gradações passíveis de não percepção numa análise quantitativa da questão. Em adição, quantidade de serviços não indica qualidade. Todos esses fatores podem, de alguma maneira, impactar os valores obtidos. De toda forma, o trabalho procura fornecer um indicador das áreas mais carentes, e busca, com isso, contribuir para o debate sobre as transferências compensatórias (FPE) em um país com acentuadas disparidades. A defasagem relativa em termos de atuação pública é preocupante e chama a atenção para as áreas desfavorecidas, que deveriam ser prioritariamente atendidas no tocante a expansões da oferta pública de serviços. Mas, como se argumenta neste trabalho, o indicador de déficit não deve ser o único critério a ser considerado, sob pena de se estimular a criação de incentivos perversos.

\subsection{Segundo Modelo: Eficiência nos Gastos Públicos}

Os resultados da avaliação da eficiência em custos estão apresentados na Tabela 2. Observa-se que a Região Sul demonstrou o melhor desempenho, onde nenhum Estado incorreu, em termos comparativos, em desperdício de recursos. Logo em seguida vem a região Sudeste, onde apenas o Espírito Santo não foi considerado eficiente. Em termos absolutos, o Estado poderia ter economizado R\$ 894.093.417,33. O desvio padrão apresentado mostra que existe grande diferença entre o Espírito Santo e os demais Estados que compõem a região.

A região Norte apresentou a terceira melhor performance. Em média, seus Estados apresentaram desperdícios de 1,23\% dos recursos utilizados. Apenas Amapá, Roraima e Tocantins foram considerados eficientes. ${ }^{17}$ Os demais Estados, juntos, deixaram de empregar adequadamente, em termos absolutos, R \$ 699.102.714,23. Os desvios padrão revelam pequena variabilidade entre os Estados analisados.

Em seguida vem a região Centro-Oeste, com um índice médio de eficiência bastante insatisfatório $(80,52 \%)$, onde apenas o Distrito Federal foi considerado eficiente. Goiás $(83,6 \%)$, Mato Grosso $(68,9 \%)$ e Mato Grosso do Sul $(69,5 \%)$ foram ineficientes. No geral, o Centro-Oeste deixou de empregar eficientemente R\$ 2.285.469,22. O desvio padrão apresentado revela grande variabilidade entre os Estados da região.

16 A técnica DEA é bastante sensível à presença de observações atípicas. Utilizou-se como critério para detecção dessas observações o método estatístico de agrupamento (cluster). Com isso, Estados atípicos ficaram impedidos de definir a fronteira tecnológica para evitar possíveis distorções.

17 As observações feitas anteriormente em relação aos novos Estados, quando da análise do primeiro modelo, são pertinentes também neste caso. 


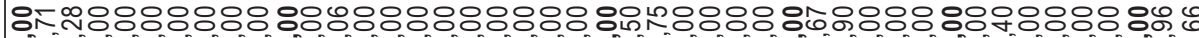

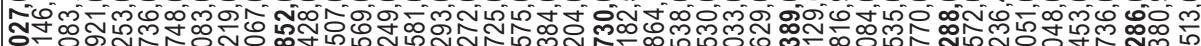
iึ

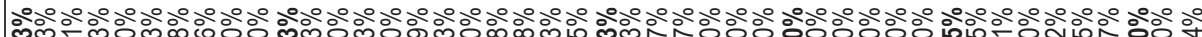
స్స $\because$ 0000

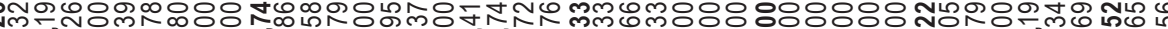

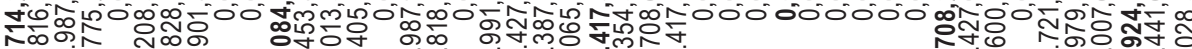

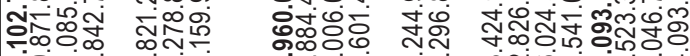

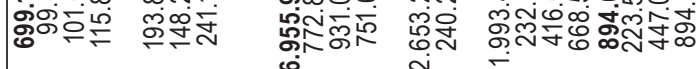

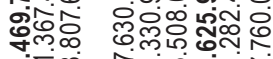

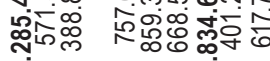

N

으

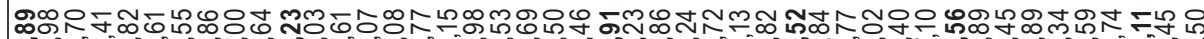
0. \%ొ

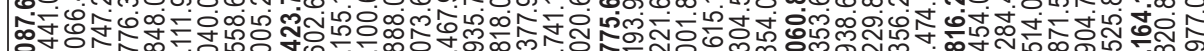
ㄴ-

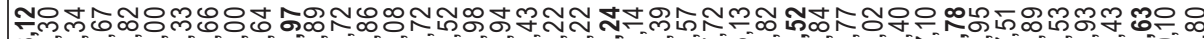

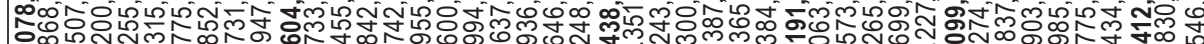

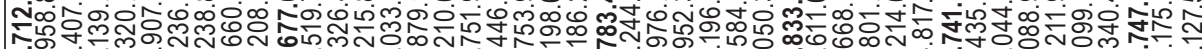

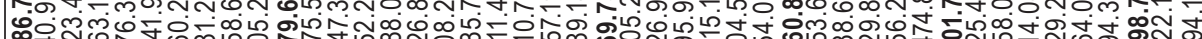

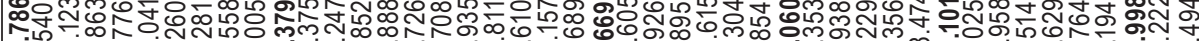

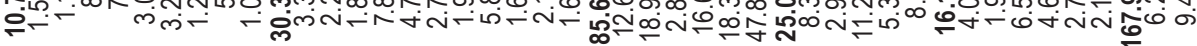

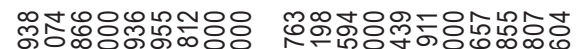
$000-000-1.000-00=0000$.

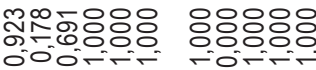

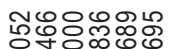
0 Or-? $\infty$ 
O Nordeste merece uma atenção especial. Em média, os Estados que integram a região apresentaram índices de eficiência de 0,76 , o que equivale a dizer que cerca de $24 \%$ dos recursos não estão sendo bem aplicados. Em termos do próprio PIB, é nesta região onde também se verificam os maiores desperdícios. Dos nove Estados nordestinos, apenas Bahia e Paraíba foram considerados eficientes. Em ordem decrescente, os Estados que mais desperdiçaram recursos foram: Ceará ( $\mathrm{R} \$ 2.653 .244 .987,95)$, Pernambuco (R $\$$ 1.993.424.991,41), Alagoas (R\$ 751.601.405,79), Sergipe (R\$ 668.541.065,76), Rio Grande do Norte (R\$ 416.024.387,72), Piauí (R \$ 232.826.427,74) e Maranhão (R \$ 240.296.818,37), perfazendo um total de R $\$ 6.955 .960 .084,74$ de recursos subutilizados. O desvio padrão apresentado na região foi o maior, se comparado com as demais regiões brasileiras, indicando grande variabilidade entre os Estados.

Essa situação é preocupante. Ao mesmo tempo que a região apresenta o maior déficit relativo quanto à oferta de serviços (déficit de cerca de $30 \%$, como se verificou no primeiro modelo), dá-se o direito de ser a região que mais desperdiça recursos. O mesmo acontece, no entanto, com outros Estados fora do Nordeste, como é o caso do Espírito Santo (Sudeste), de Rondônia (Norte) e de Goiás (Centro-Oeste). Esta situação ressalta o fato de que não se trata apenas de suprir carências, regionais ou não, mas também de fornecer os incentivos corretos para que as deficiências possam ser sanadas. A mensagem parece clara: distribuir verbas para as áreas desfavorecidas, simplesmente, pode não resolver a questão.

\subsection{Terceiro Modelo: Eficiência Arrecadatória}

A Tabela 3 apresenta os resultados referentes à eficiência arrecadatória. Observa-se que, em geral, os Estados tiveram desempenho similar e revelaram baixa perda tributária. De toda forma, percebe-se um ligeiro desempenho melhor no Sudeste, onde todos os Estados foram considerados eficientes. No Centro-Oeste, apenas um Estado foi considerado ineficiente: Mato Grosso do Sul, que deixou de arrecadar R \$ 4.826.956,11. Logo em seguida vem a região Norte. Composta de sete membros, apenas Pará (perda tributária em relação ao PIB de $0,05 \%)$ e Rondônia $(0,02 \%)$ não foram considerados eficientes. Esses Estados deixaram de arrecadar, em termos absolutos, um total de R\$ 12.312.772,23.

Na Região Nordeste, apenas a Bahia foi considerada eficiente. As piores situaçóes foram encontradas em Pernambuco $(0,06 \%)$, Ceará $(0,03 \%)$, Paraíba $(0,04 \%)$, Maranhão, Sergipe, Alagoas, Piauí (0,03\%) e Rio Grande do Norte (0,02\%). Em termos absolutos, essas porcentagens equivalem a R \$ 17.479.537,72 (Pernambuco), R \$ 6.036.591,52 (Ceará), R \$ 4.356.857,22 (Paraíba), R \$ 3.394.123,16 (Maranhão), R \$ 2.535.171,74 (Sergipe), R \$ 2.003.925,82 (Alagoas), R \$ 1.676.624,66 (Piauí), e R \$ 2.257.035,80 (Rio Grande do Norte). 
*⿻尸丨

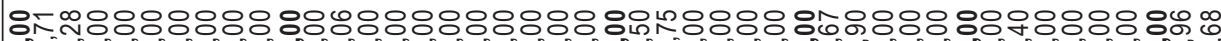

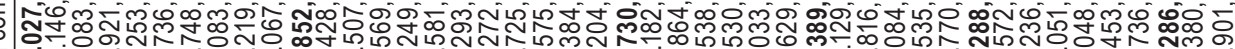

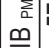

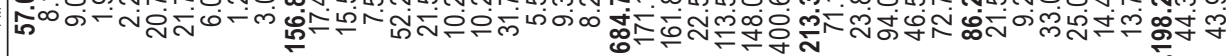
$\frac{m}{\alpha}$

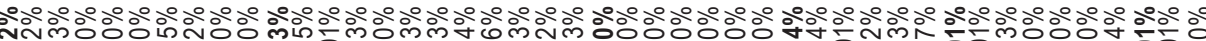

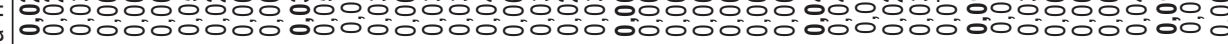
बे

พొน

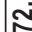

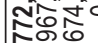

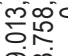

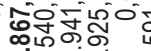

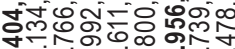
กำ 宁 8ृ่n்

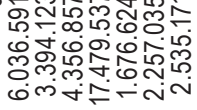


离

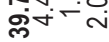

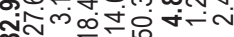

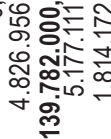

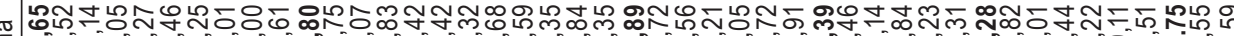

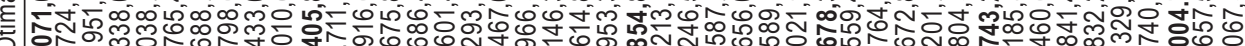

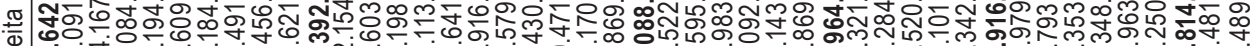
Nं ம

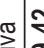

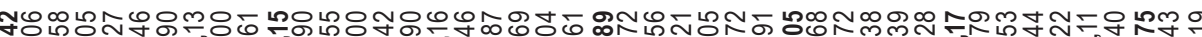

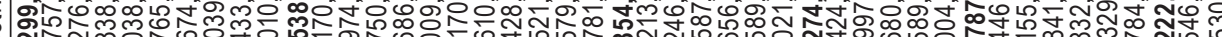

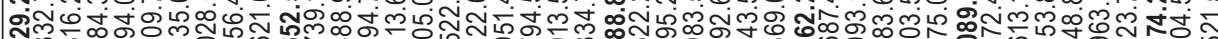
作

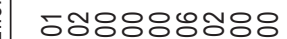

응ㅇㅇㅇㅇㅇㅇㅇㅛ

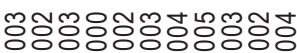

양ㅇㅇㅇㅇㅇㅇ

การกา

Оㅇํㅇㅇํㅇ

훙ㅇㅇㅇㅇㅇㅇㅠ

ชิธิ์

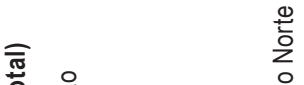


A pior performance no esforço de arrecadação ficou com a Região Sul. Nenhum Estado desta região foi eficiente. Paraná $(0,08 \%)$, Santa Catarina $(0,03 \%)$ e Rio Grande do Sul $(0,02 \%)$ deixaram de arrecadar, em termos absolutos, R\$ 82.902.404,34. Este resultado para a região Sul, no entanto, não deve ser hiperdimensionado. A diferença do Estado com pior performance em relação à fronteira eficiente não chega a 1\% (caso do Paraná, com $0,8 \%)$. Isto revela que os Estados brasileiros encontram-se bastante equilibrados no que toca à eficiência na arrecadação pública e que eventuais negligências neste aspecto revelaram-se pequenas. ${ }^{18}$

\subsection{Distribuição Ótima das Transferências Redistributivas}

Nesta seção, as análises anteriores serão integradas para se obter o repasse ótimo de transferências $T^{*}$ para cada Estado, o que será conseguido levando em consideração a oferta de serviços eqüitativos $y^{*}(N)$, o custo mínimo para a prestação dos mesmos $C^{*}\left(y^{*}\right)$ e o potencial de arrecadação disponível em cada Estado $R T^{*}$. Assim, sugere-se que o repasse deve ser feito da seguinte forma: $T^{*}=C^{*}\left(y^{*}\right)-R T^{*}$. Com base neste critério, ${ }^{19}$ percebe-se que os Estados teriam verbas suficientes para uma prestação eficiente e eqüitativa de serviços. As transferências contribuem tão-somente para uma eventual complementação das receitas tributárias, caso estas não sejam suficientes para prestar os serviços necessários.

A Tabela 4 fornece o montante ótimo de transferências $\left(T^{*}\right)$, a partir da diferença entre o vetor de custos mínimos de serviços eqüitativos $C^{*}\left(y^{*}\right)$ e o potencial de arrecadação local $R T^{*}$. Os resultados mostram que, partindo do critério proposto, todos os Estados brasileiros necessitam receber verbas compensatórias. Tal fato pode ser comprovado pelos valores positivos da coluna de transferências ótimas. Ressalta-se, no entanto, que além do FPE os Estados também recebem outros tipos de transferências e, portanto, o valor adequado deveria corresponder à diferença entre os repasses ótimos e as demais transferências, ${ }^{20}$ conforme consta da quarta coluna da tabela. A coluna seguinte apresenta a proporção desses repasses ótimos em relação ao PIB de cada Estado, o que facilita uma análise comparativa. A penúltima coluna corresponde à diferença entre o FPE ótimo e o FPE efetivo em relação ao PIB e, por fim, a última coluna fornece a população de cada Estado.

18 Piancastelli, Miranda e Vasconcelos (2004) estudaram, a partir de outro enfoque metodológico, a questão do esforço fiscal dos Estados brasileiros e encontraram dispersão relativamente maior. Os Estados do Sul apresentam-se relativamente bem posicionados, mas mostraram tendência nitidamente negativa no período sob análise (1987-1999).

19 Ver Gasparini e Melo (2004) para mais detalhes.

20 Além do FPE, os Estados recebem outros tipos de transferência, dentre as quais destacamos: FUNDEF, Lei Complementar No 87/1996 (transferência para compensação da isenção do ICMS pelos Estados exportadores) e SUS. 


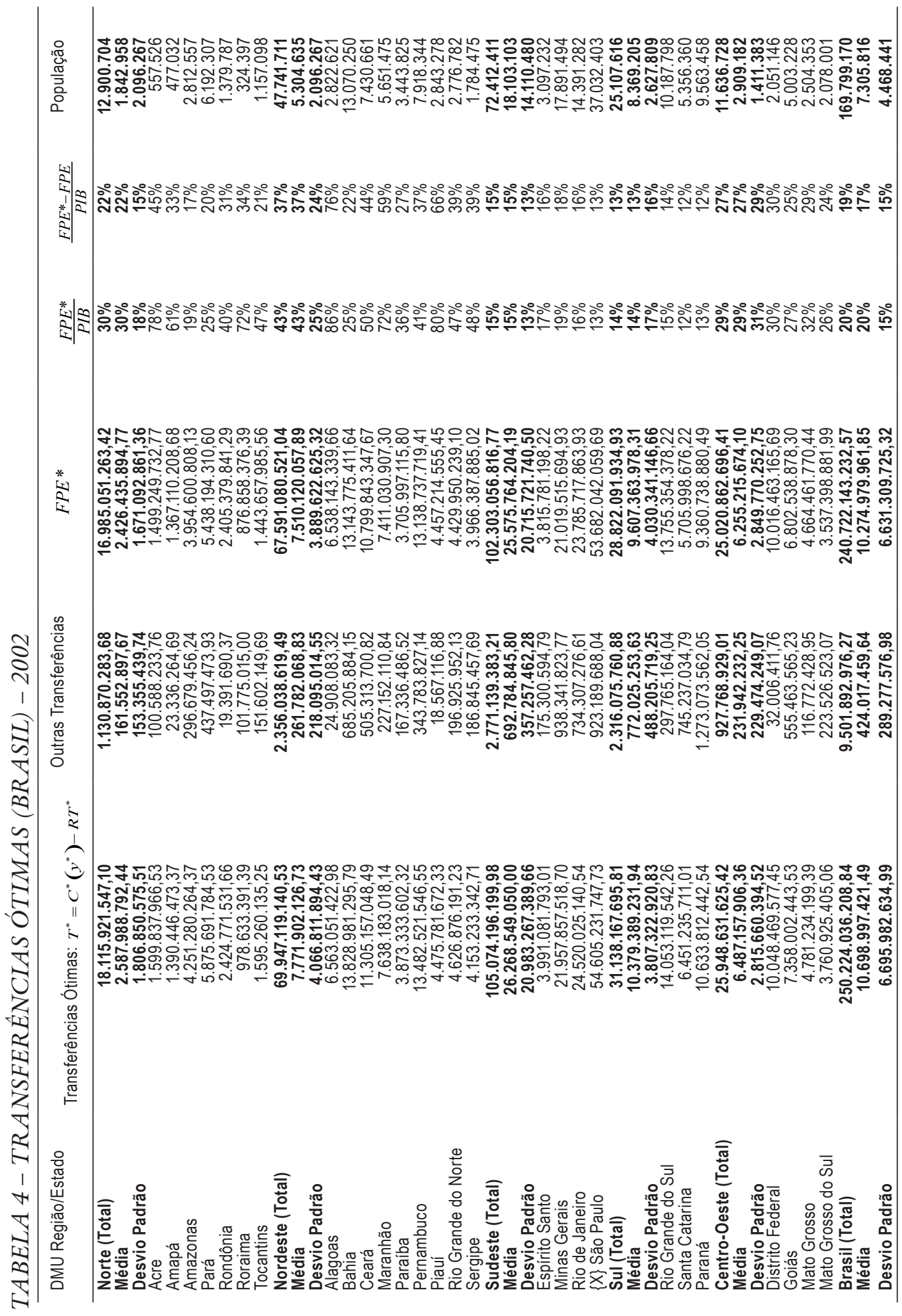


Em termos regionais, observa-se que a região Sul encontra-se em melhor situação. A necessidade de complementação de verbas para reduzir os desequilíbrios dos serviços prestados corresponde a $14 \%$ do PIB da região. Dentre os três Estados que a integram, o Rio Grande do Sul revelou necessitar de maiores repasses (15\% do seu PIB), seguido do Paraná (13\%) e de Santa Catarina (12\%). Vale ressaltar que a região possui o terceiro maior contingente populacional entre as cinco regiões brasileiras.

A segunda melhor performance ficou com a região Sudeste, que possui o maior contingente populacional (necessidade média de complementação em relação ao PIB de 15\%). Dos quatro Estados da região, Minas Gerais (19\%) apresentou a maior necessidade de aporte complementar de recursos, seguida do Espírito Santo (17\%), do Rio de Janeiro (16\%) e de São Paulo (13\%).

A seguir vem a Região Centro-Oeste (29\%). Dos quatro Estados presentes, a pior situação foi verificada no Estado do Mato Grosso (32\%), acompanhado do Distrito Federal (30\%), Goiás (27\%) e Mato Grosso o Sul (26\%). Foi constatada grande variabilidade de necessidades de complementação de verbas, além de ali estar concentrada a menor população regional.

Em quarto lugar está a região Norte, com necessidade de complementação de recursos de cerca de $30 \%$ do PIB. Em pior situação encontra-se o Estado do Acre (78\%), seguido de Roraima (72\%), Amapá (61\%), Tocantins (47\%), Rondônia (40\%), Pará (25\%) e Amazonas (19\%). Esta região possui o segundo menor contingente populacional.

Por fim, encontra-se em pior situação a região Nordeste (43\%). Os nove Estados, em ordem decrescente de necessidade do recebimento de verbas em proporção ao PIB, estão assim dispostos: Alagoas (86\%), Piauí (80\%), Maranhão (72\%), Ceará (50\%), Sergipe (48\%), Rio Grande do Norte (47\%), Pernambuco (41\%), Paraíba (36\%) e Bahia (25\%). A região possui o segundo maior contingente populacional.

Com base na metodologia utilizada foi possível calcular um novo coeficiente de repasse do FPE para cada Estado. ${ }^{21}$ Estes resultados estão expressos na Tabela 5, e relevam um fato importante: o critério aqui sugerido recomenda uma redução dos coeficientes das regióes Norte e Nordeste (todos os Estados destas duas regióes deveriam ter seus

21 A Lei Complementar 104/89 definiu coeficientes individuais para fins de distribuição do FPE (ver segunda coluna da Tabela 5). Para calcular a parcela de cada Estado, multiplica-se o total a ser distribuído (21,5\% da receita bruta arrecadada pela União com o Imposto de Renda - IR e com o Imposto sobre Produtos Industrializados - IPI, retirados os incentivos fiscais e as restituições), pelos respectivos coeficientes. A forma de determinação desses coeficientes não é muito clara, embora se leve em conta área territorial, população e inverso da renda per capita de cada Estado (mais detalhes podem ser obtidos pela leitura dos artigos 86 a 90 da Lei N. 5.172 de 25.10.1966 - Código Tributário Nacional). A Lei Complementar N. 62/89 estabeleceu como seria feita a distribuição e definiu, também, que do valor total do FPE, 85\% iriam para os Estados das Regiões Norte, Nordeste e Centro-Oeste $(25,37 \%, 52,46 \%$ e $7,17 \%$, respectivamente) e apenas $15 \%$ paras as Regiốes Sul e Sudeste (6,52\% e 8,48\%). 
coeficientes reduzidos) ao lado de uma elevação dos coeficientes referentes ao Sudeste (em todos os Estados), ao Centro-Oeste (à exceção do Mato Grosso e de Goiás, onde a variação é irrelevante), e Sul (em todos os Estados).

TABELA 5 - DISTRIBUIÇÃO DO FPE POR REGIÕES/ESTADOS - 2002

\begin{tabular}{|c|c|c|c|}
\hline Estado/Região & \% de Participação* & $\mathrm{FPE}^{*}$ & $\%$ de Participação ${ }^{+}=\frac{F P E_{i}{ }^{*}}{\sum_{j=1}^{m} F P E^{*}}$ \\
\hline Acre & 3,421 & $1.499 .249 .732,77$ & $0,623 \%$ \\
\hline Amapá & 3,412 & $1.367 .110 .208,68$ & $0,568 \%$ \\
\hline Amazonas & 2,7904 & $3.954 .600 .808,13$ & $1,643 \%$ \\
\hline Pará & 6,112 & $5.438 .194 .310,60$ & $2,259 \%$ \\
\hline Rondônia & 2,8156 & $2.405 .379 .841,29$ & $0,999 \%$ \\
\hline Roraima & 2,4807 & $876.858 .376,39$ & $0,364 \%$ \\
\hline Tocantins & 4,34 & $1.443 .657 .985,56$ & $0,600 \%$ \\
\hline Norte (Total) & 25,3717 & $16.985 .051 .263,42$ & $7,056 \%$ \\
\hline Alagoas & 4,1601 & $6.538 .143 .339,66$ & $2,716 \%$ \\
\hline Bahia & 9,3962 & $13.143 .775 .411,64$ & $5,460 \%$ \\
\hline Ceará & 7,3369 & $10.799 .843 .347,67$ & $4,486 \%$ \\
\hline Maranhão & 7,2182 & $7.411 .030 .907,30$ & $3,079 \%$ \\
\hline Paraíba & 4,7889 & $3.705 .997 .115,80$ & $1,540 \%$ \\
\hline Pernambuco & 6,9002 & $13.138 .737 .719,41$ & $5,458 \%$ \\
\hline Piauí & 4,3214 & $4.457 .214 .555,45$ & $1,852 \%$ \\
\hline Rio Grande do Norte & 4,1779 & $4.429 .950 .239,10$ & $1,840 \%$ \\
\hline Sergipe & 4,1553 & $3.966 .387 .885,02$ & $1,648 \%$ \\
\hline Nordeste (Total) & 52,4551 & $67.591 .080 .521,04$ & $28,078 \%$ \\
\hline Distrito Federal & 0,6902 & $10.016 .463 .165,69$ & $4,161 \%$ \\
\hline Goiás & 2,8431 & $6.802 .538 .878,30$ & $2,826 \%$ \\
\hline Mato Grosso & 2,3079 & 4.664.461.770,44 & $1,938 \%$ \\
\hline Mato Grosso do Sul & 1,332 & $3.537 .398 .881,99$ & $1,469 \%$ \\
\hline Centro-Oeste (Total) & 7,1732 & $25.020 .862 .696,41$ & $10,394 \%$ \\
\hline SUBTOTAL I & 85 & $109.596 .994 .480,87$ & $45,528 \%$ \\
\hline Espírito Santo & 1,5 & $3.815 .781 .198,22$ & $1,585 \%$ \\
\hline Minas Gerais & 4,4545 & $21.019 .515 .694,93$ & $8,732 \%$ \\
\hline Rio de Janeiro & 1,5277 & $23.785 .717 .863,93$ & $9,881 \%$ \\
\hline São Paulo & 1 & $53.682 .042 .059,69$ & $22,300 \%$ \\
\hline Sudeste (Total) & 8,4822 & $102.303 .056 .816,77$ & $42,498 \%$ \\
\hline Rio Grande do Sul & 2,8832 & $13.755 .354 .378,22$ & $5,714 \%$ \\
\hline Santa Catarina & 2,3548 & $5.705 .998 .676,22$ & $2,370 \%$ \\
\hline Paraná & 1,2798 & $9.360 .738 .880,49$ & $3,889 \%$ \\
\hline Sul (Total) & 6,5178 & $28.822 .091 .934,93$ & $11,973 \%$ \\
\hline SUBTOTAL II & 15 & $131.125 .148 .751,70$ & $54,472 \%$ \\
\hline Brasil (Total) & 100 & $240.722 .143 .232,57$ & $100 \%$ \\
\hline
\end{tabular}

Fonte: * Secretaria do Tesouro Nacional (2004).

+Critério proposto pelo trabalho. 
O confronto desses resultados com os da Tabela 4 mostra que, apesar da região Nordeste necessitar de maior aporte de recursos em termos do próprio PIB, os valores absolutos que o atual critério de repartição do FPE lhe destina já beneficiam a região nessa direção. O mesmo ocorre com a região Norte. Convém lembrar que é exatamente no Nordeste onde se verificaram os maiores indícios de ineficiência na prestação de serviços públicos estaduais. Esta constatação reforça as preocupações sobre os possíveis resultados adversos que as políticas redistributivas poderiam estar gerando em termos de eficiência pública.

Este trabalho procura contribuir para um maior entendimento dos problemas atualmente enfrentados pelo Brasil, no campo do Federalismo Fiscal. Ao avaliar o critério de rateio do FPE, cujo objetivo é a diminuição dos desequilíbrios regionais, levou-se em consideração o debate teórico acerca dos possíveis desestímulos que esses repasses podem gerar. É importante salientar que a construção de indicadores de gastos, de arrecadação e de déficit de serviços pode servir de instrumento para nortear políticas públicas compensatórias. O quadro traçado até aqui, no entanto, sugere que é preciso repensar os atuais critérios de rateio do Fundo, para que, de fato, ele consiga diminuir os desequilíbrios socioeconômicos entre os Estados, sem desestimular a gestão pública eficiente e o esforço arrecadatório.

\section{CONCLUSÃO}

Dada a irregular distribuição das bases tributárias existentes em nosso País, o FPE tem o objetivo constitucional de promover o equilíbrio socioeconômico entre as unidades federativas. Entretanto, os efeitos perversos que essas transferências podem gerar na gestão dos recursos públicos e no esforço tributário dos Estados constituem alvo de debate teórico, podendo comprometer o objetivo central dos repasses de verbas. Diante desse contexto, o trabalho procurou avaliar o FPE em três etapas: necessidade de serviços para equilibrar a situação dos Estados, eficiência na provisão de bens e serviços e esforço arrecadatório.

Com base no primeiro modelo foi possível estimar uma fronteira para avaliar o déficit relativo nos serviços prestados, partindo do conceito de eqüidade de acesso. Os resultados desta estimação mostraram que a Região Sul, em média, obteve a melhor disponibilidade de serviços para as mesmas necessidades. Em seguida, vêm as Regióes Sudeste, CentroOeste, Norte e, por último, o Nordeste. Os Estados do Acre, Amapá, Roraima, Minas Gerais, Rio de Janeiro, São Paulo, Rio Grande do Sul, Santa Catarina, Paraná, Mato Grosso, Mato Grosso do Sul e o Distrito Federal apresentaram as melhores disponibilidades de serviços públicos. A pior situação foi apresentada por Alagoas, que dispõe apenas de $57 \%$ dos serviços ofertados em Estados com melhor disponibilidade relativa. Da 
mesma forma, Estados como Ceará, Maranhão, Pernambuco e Piauí dispõem de menos de $70 \%$ dos serviços ofertados em áreas com melhor situação. Constata-se, com esses resultados, que apesar das intenções constitucionais em relação ao FPE, ainda persistem acentuadas disparidades na oferta de serviços entre os Estados do País. Em média, as unidades federativas tiveram à sua disposição uma oferta de $88 \%$ dos serviços disponíveis na fronteira.

No segundo modelo (eficiência nos gastos), o objetivo principal foi promover um mecanismo de avaliação da gestão pública. A análise mostrou que, em média, a Região Sul apresentou o menor desperdício de recursos, seguida das Regiões Sudeste, Norte, Centro-Oeste e Nordeste. Entre os 27 Estados brasileiros, Amapá, Bahia, Distrito Federal, Minas Gerais, Paraíba, Paraná, Rio de Janeiro, Rio Grande do Sul, Roraima, Santa Catarina, São Paulo e Tocantins não apresentaram desperdícios de recursos. De uma forma geral, não foi possível constatar qualquer padrão entre eficiência nos gastos e renda dos Estados.

No terceiro modelo (eficiência Arrecadatória), a região que, em média, obteve o melhor resultado foi a Sudeste, seguida das regiões Centro-Oeste, Norte, Nordeste, e Sul. Quanto aos Estados individualmente, encontrou-se que Acre, Amapá, Amazonas, Roraima, Tocantins, Bahia, Espírito Santo, Minas Gerais, Rio de Janeiro, São Paulo, Distrito Federal, Goiás e Mato Grosso não incorreram em perdas tributárias. Tampouco foi constatado qualquer padrão entre PIB e perdas de Receitas.

A partir das três etapas anteriores, procurou-se estabelecer um montante ótimo para o repasse das transferências, de modo a preservar a eqüidade entre os Estados e não gerando desestímulos à eficiência pública, tanto nos gastos quanto na arrecadação. Observou-se que todos os Estados brasileiros necessitariam receber transferências compensatórias. A Região Nordeste apresentou a situação menos favorável, significando maior necessidade de receber transferências proporcionais ao PIB. Em seguida vêm as Regiões Norte, Centro-Oeste, Sudeste e Sul. Observa-se, também, que os repasses de verbas do FPE não foram suficientes para equilibrar o nível de serviços entre os Estados brasileiros. Em contrapartida, há indícios de desperdícios de recursos públicos justamente nas regiões que deveriam ser mais favorecidas.

Esses resultados podem ser considerados indicadores importantes para subsidiar decisóes sobre políticas de distribuição de recursos, de sorte a que o FPE atinja, efetivamente, os objetivos previstos. Os critérios atuais de rateio dos recursos do FPE baseiam-se em coeficientes fixos, cuja determinação não é clara e foi feita há muito tempo. Assim, os resultados apresentados neste estudo, que levam em consideração o potencial de arrecadação de cada Estado, a gestão dos recursos públicos, as disparidades regionais e os demais tipos de transferências podem dar uma contribuição importante para esse debate. 
Vale ressaltar o quanto é importante tomar alguns cuidados em relação aos resultados obtidos. Em primeiro lugar, o estudo utilizou observações para apenas um ano, o que pode gerar distorçôes devido a erros de medida ou a ruídos que eventualmente possam estar presentes nos dados. Além disso, a estimação foi feita a partir de indicadores de serviços e custos que nem sempre reproduzem, com fidelidade, a complexidade da situação. Outras limitações foram colocadas durante as análises. É de grande relevância que extensões e novas alternativas sejam propostas, para que sejam alcançadas transformações efetivas em direção a um desenho federativo que favoreça o bom desempenho público. Destaca-se, ainda, a necessidade de ampliação (em especial no horizonte temporal) e de melhora da base de dados, principalmente no que tange às áreas de justiça e segurança. A incorporação de novas técnicas, certamente, facilitará a verificação da sensibilidade dos resultados obtidos.

\section{REFERÊNCIAS BIBLIOGRÁFICAS}

Ali, A. I.; Seiford, L. M. Translation invariance in data envelopment analysis. Operations Research Letters, 9, p. 403-405, 1990.

Bauer, P. W. Recent developments en the econometrics estimation of frontiers. Journal of Econometrics, v. 46, n. 1/2, p. 29-56, Oct/Nov. 1990.

Banker, R.; Charnes, A.; Cooper, W. W. Some models for estimating technical and scale inefficiencies in data envelopment analysis. Management Science, 30, p. 1078-1092, 1984.

Charnes, A.; Cooper, W. W.; Rhodes, E. Measuring the efficiency of decision making units. European Journal of Operational Research, 2, p. 429-444, 1978.

Cossio, F. A. B. Disparidades econômicas inter-regionais, capacidade de obtenção de recursos tributários, esforço fiscal e gasto público no federalismo fiscal brasileiro. $21^{\circ}$ Prêmio BNDES de Economia. Rio de Janeiro. 1998. Disponível em: <www.bndes.gov. br/conhecimento/premio/pr211.pdf>. Acesso em 04 abr 2004.

Constituição Federal do Brasil. Constituição da República Federativa do Brasil. Brasília - DF: Senado, 1988.

Farrel, M. J. The measurement of productive efficiency. Journal of the Statistical Society, v. 120, n. 3, p. 253-281, 1957.

Forsund, F.; Lovell, C. A. K.; Schidt, P. A survey of frontier production functions and of their relationship to efficiency measurement. Journal of Econometrics, 13, p. 5-25, 1980.

Gasparini, E. Carlos; Ramos, F. S. Desigualdade relativa dos serviços de saúde entre regiões e estados brasileiros. Revista de Econometria. Brasil, v. 24, n. 1, p. 1-34, 2004. 
Gasparini, E. Carlos; Melo, L. S. Cristiano. Equidade e eficiência municipal: uma avaliação do Fundo de Participação dos Municípios - FPM. STN - DF, 2004.

Gasparini, E.Carlos; Ramos, F. S. Efetividade e eficiência no ensino médio brasileiro. Economia Aplicada. São Paulo, v. 7, n. 2, p. 389-411, abr./jun. 2003.

. Avaliação da eficiência pública municipal: o caso de Pernambuco. Revista Econômica do Nordeste, v. 34, n. 2, p. 288-307, abr/jun. 2003.

Incentivos à eficiência na descentralização fiscal brasileira: o caso dos municípios paulistas. Pesquisa e Planejamento Econômico, Rio de Janeiro: v. 34, n. 1, p. 1-70, 2004.

Gomes, G. M.; Mac Dowel M. C. Descentralização política, federalismo fiscal e criação de municípios: o que é mau para o econômico nem sempre é bom para o social. Texto para Discussão, 706, Brasília: IPEA, fev. 2000.

. Os elos frágeis da descentralização - observações sobre as finanças dos municípios brasileiros, 1995. Curso de Gestão Urbana e de Cidades - EG/FJP WBI PBH ESAF IPEA, março de 2000.

Koopmans, T. C. (ed.), Activity analysis of production and allocation. New York: John Wiley, 1951.

Medeiros, M. M. C. Princípios de justiça na alocação de recursos em saúde. Texto para Discussão no 687, IPEA. 1999.

Mendes, M. J. Proposta para um novo federalismo fiscal: novos critérios de distribuição para o FPM e criação do Fundo de Participação das Regiões Metropolitanas. 2002. Disponível em: <http://www.braudel.org.br/marcosm.htm>. Acesso em abr. 2004.

Pastor, J. Translation invariance in data envelopment analysis: a generalization. Annals of Operations Research 66, p. 93-102, 1996.

Piancasteli, M.; Miranda, B. R.; Vasconcelos, R. J. Esforço fiscal dos estados brasileiros. Texto para Discussão, 1045, Brasília: IPEA, set. 2004.

Pontual, E. R. Capacidade e eficácia tributária dos municípios do Rio Grande do Sul. Anais do $27^{\circ}$ Encontro Nacional de Economia, Belém: ANPEC, 1999, v. 3.

Puig-Junoy, J. Radial measures of public services deficit for regional allocation of public funds. Department of Economics and Business, Health and Economics Research Centre (CRES), Universitat Pompeu Fabra, 1999. Mimeografado.

Reis, J. E.; Blanco A. F. Capacidade tributária dos estados brasileiros. Texto para Discussão no 404, IPEA., 1996.

Schwengber, S. B.; Ribeiro, E. P. O impacto do Fundo de Participação (FPE) no esforço tributário dos estados: uma estimativa do potencial de arrecadação do ICMS. IV Prêmio Tesouro Nacional. Brasília: Tesouro Nacional, 2000.

Seiford, L. M.; Thrall, R. M. Recent developments in DEA. The mathematical programming approach to frontier analysis. Journal of Econometrics 46, p. 7-38, 1990. 
Serra, J.; Afonso, J. R. R. Federalismo fiscal à brasileira: algumas reflexões. Revista do BNDES, Rio de Janeiro, v. 6, n. 12, p. 3-30, Dez. 1999.

Shah, A. The Reform of intergovernamental fiscal relations in developing and emerging markets economies. Policy and Research Series, N. 23, The World Bank, 1994.

STN. Secretaria do Tesouro Nacional. Cartilha FPE/FPM. Disponível em: < http://www. stn.fazenda.gov.br/servicos/biblioteca_virtual/index.asp >. Acesso em jul. 2004.

ANEXO I - RELAÇÃO, FONTE E ANO 22 DAS VARIÁVEIS UTILIZADAS

\section{Primeiro Modelo (Equidade dos Serviços Públicos Estaduais)}

\section{Necessidades}

$n_{1}=$ População em idade escolar de 5 a 19 anos - Ministério da Educação (INEP) $-2002$

$n_{2}=$ Número de Óbitos de Doenças Parasitárias e Infecciosas - Ministério da Saúde (DATASUS) - 2002

$n_{3}=$ Número de Residências sem instalações Sanitárias - Ministério da Saúde $-2002$

$n_{4}=$ Número da População Total - Ministério da Saúde -2002

$n_{5}=$ P0rcentual da população em estado de pobreza - Ministério da Saúde - 2001

$n_{6}=$ Razão da renda - Ministério da Saúde -2002

$n_{7}=$ Taxa de Trabalho infantil - Ministério da Saúde -2002

\section{Disponibilidade de Serviços}

$y_{1}=$ Odontólogos por 1000hab $-($ DATASUS $)-2002$

$y_{2}=$ Enfermeiros por 1000hab $-($ DATASUS $)-2002$

$y_{3}=$ Médicos por 1000hab $-($ DATASUS $)-2002$

$y_{4}=$ Técnicos Auxiliares em enfermagem por 1000 hab - (DATASUS) - 2002

$y_{5}=$ Número de leitos hospitalares - (DATASUS) -2002

22 Devido à inexistência de dados, nem todas as variáveis puderam ser consideradas para os mesmos anos. Ressalta-se que, apesar dessa falta de homogeneidade, os itens considerados são indicadores que não mudam radicalmente no intervalo de tempo observado. 
$y_{6}=$ Número de matrículas no ensino fundamental - Ministério da Educação (INEP) $-2002$

$y_{7}=$ Número de matrículas no ensino médio - Ministério da Educação (INEP) $-2002$

$y_{8}=$ População com mais de 8 anos de estudo - (DATASUS) -2002

$y_{9}=$ Número de docentes no ensino fundamental - Ministério da Educação (INEP) $-2002$

$y_{10}=$ Número de estabelecimentos de educação básica - Ministério da Educação (INEP) $-2002$

$y_{11}=$ Número de docentes no ensino médio e profissional- Ministério da Educação (INEP) $-2002$

$y_{12}=$ Número de docentes exercendo atividades em sala - Ministério da Educação (INEP) $-2002$

$y_{13}=$ Cobertura de esgotamento sanitário - IBGE -2002

$y_{14}=$ Número de domić́lios com energia elétrica - IPEA - 2002

$y_{15}=$ Pistas estaduais pavimentadas - Dpto. Nacional de infra-estrutura de transportes (DNIT) -2003

$y_{16}=$ Número de Óbitos Violentos (IPEA) - 2002

Segundo Modelo (Eficiência em Gastos)

\section{Custos dos Serviços}

$\mathrm{C}($ Custos $)=$ Despesas Correntes - Secretaria do Tesouro Nacional -2002

2. Serviços Ofertados

$Y=\left(y_{1}, y_{2}, \ldots, y_{16}\right)-$ Mesmo vetor de Serviços do primeiro modelo.

Terceiro Modelo (Eficiência em Arrecadação)

\section{Receitas}

RT $($ Receitas Tributárias $)=$ Receitas Tributárias Próprias - Secretaria do Tesouro Nacional - 2002 


\section{Indicadores de Base Tributária}

$\mathrm{B}_{1}=$ Renda Total $\left(\mathrm{PIB}_{\mathrm{pm}}\right)$ - Número de Internações Hospitalares - IBGE - 2002

$\mathrm{B}_{2}=$ População Urbana - IPEA -2003

$\mathrm{B}_{3}=$ Frota de Veículos - Departamento Nacional de Trânsito (DENATRAN) $-2003$

ANEXO II - ESTATÍSTICA DESCRITIVA DAS VARIÁVEIS UTILIZADAS

\begin{tabular}{|c|c|c|c|c|}
\hline & Valor mínimo & Valor máximo & Média & Desvio padrão \\
\hline \multicolumn{5}{|c|}{ Modelo 1} \\
\hline$n_{1}$ & 162.472 & 13.385 .708 & $2.528 .350,67$ & $2.784 .431,82$ \\
\hline$n_{2}$ & 55.490 & 4.305 .434 & $1.253 .616,70$ & $1.161 .936,63$ \\
\hline$n_{3}$ & 337.253 & 37.630 .105 & $6.384 .658,37$ & $7.741 .967,08$ \\
\hline$n_{4}$ & 45 & 9.975 & $1.500,63$ & $2.126,23$ \\
\hline$n_{5}$ & 163 & 10.437 & $2.290,59$ & $2.250,10$ \\
\hline$n_{6}$ & 2.491 & 168.416 & $39.735,85$ & $45.718,16$ \\
\hline$n_{7}$ & 346.866 & 38.177 .734 & $6.467 .886,37$ & $7.844 .371,76$ \\
\hline$y_{1}$ & 0,21 & 1,86 & 0,71 & 0,41 \\
\hline$y_{2}$ & 0,20 & 1,36 & 0,47 & 0,25 \\
\hline$y_{3}$ & 0,65 & 5,54 & 1,72 & 1,10 \\
\hline$y_{4}$ & 0,99 & 7,33 & 2,49 & 1,48 \\
\hline$y_{5}$ & 659,00 & $21.028,00$ & $5.321,85$ & $5.108,21$ \\
\hline$y_{6}$ & $80.220,00$ & $3.353 .583,00$ & $554.086,63$ & $682.096,61$ \\
\hline$y_{7}$ & $19.938,00$ & $1.785 .747,00$ & $273.800,07$ & $360.155,99$ \\
\hline$y_{8}$ & 24,81 & 64,12 & 41,62 & 9,54 \\
\hline$y_{9}$ & $4.202,00$ & $134.515,00$ & $23.978,78$ & $29.541,79$ \\
\hline$y_{10}$ & 412,00 & $6.743,00$ & $1.637,44$ & $1.461,56$ \\
\hline$y_{11}$ & 697,00 & $81.351,00$ & $12.490,41$ & $16.836,09$ \\
\hline$y_{12}$ & $5.882,00$ & $197.989,00$ & $35.836,15$ & $42.453,29$ \\
\hline$y_{13}$ & $202.305,00$ & $34.945 .954,00$ & $4.164 .464,78$ & $7.063 .250,53$ \\
\hline$y_{14}$ & $64.736,42$ & $10.321 .503,82$ & $1.567 .845,09$ & $2.125 .643,36$ \\
\hline$y_{15}$ & 40,00 & $12.321,30$ & $3.146,38$ & $3.199,63$ \\
\hline$y_{16}$ & 262,00 & $20.898,00$ & $3.068,26$ & $4.272,12$ \\
\hline \multicolumn{5}{|c|}{ Modelo 2} \\
\hline$C$ & $558.660 .731,00$ & $47.854 .050 .384,82$ & $6.222 .175 .830,10$ & $9.475 .240 .983,17$ \\
\hline \multicolumn{5}{|c|}{ Modelo 3} \\
\hline$R T$ & 9,47 & 14,59 & 10,00 & 1,00 \\
\hline$B_{1}$ & 1.219 & 400.629 & $44.397,63$ & $80.059,86$ \\
\hline$B_{2}$ & 367.701 & 39.239 .362 & $6.633 .634,59$ & $8.042 .891,88$ \\
\hline$B_{3}$ & 43.191 & 12.665 .366 & $1.357 .722,26$ & $2.499 .133,10$ \\
\hline
\end{tabular}

